\title{
Study on Prestressed Fabricated Connections
}

\author{
Qi Hu ${ }^{1, a}$ \\ ${ }^{1}$ Beijing Shunyi District Linhe Street No. 15, China \\ aqihu@cscec.com
}

\begin{abstract}
Keywords: Prestressed prefabricated; Frame; Beam column connection; Future research direction. Abstract. Compared with the traditional frame structure, the prestressed prefabricated frame structure has many advantages, of which the mechanical performance of the beam column connection is very important. In this paper, the present research on prestressed fabricated connections at home and abroad is expounded. The research results of fabricated connections at home and abroad are summarized in terms of construction; mechanical performance and engineering practicability are summarized. Finally, it is pointed out of the problems existing in the practical application of prestressed fabricated connections and the future research direction, which will provide reference for other researchers.
\end{abstract}

\section{Introduction}

Compared with the cast-in-place structure, the fabricated structure has great advantages in energy saving, environmental protection, green and so on. It meets the needs of modern building development. The industrial production of fabricated structural component can guarantee the reliability of component strength, but the assembly of the structure still needs to be carried out on the spot, and the mechanical performance of the connections is essential to the safety of the whole structure.

Compared with the cast-in-situ precast structure, the research on the prefabricated structure connections is relatively less, due to the lack of experimental data, it is granted that the deformation of the prefabricated structure connections is mostly is concentrated in the component connection, leading that nonlinear deformation properties of prefabricated structures is inferior to the cast-in-place structure, thus the use of prefabricated structures is greatly limited under this influence. In order to study the anti-seismic performance of fabricated connections and to promote the use of fabricated structures, a series of studies have been carried out on this kind of structure.

The fabricated structure connections are divided into three kinds, the first kind is only by ordinary steel connections, the second is the link of prestressed tendons and third is through mixed connection by ordinary reinforced (damper) and fabricated tendons. The research on connections only through ordinary steel bars is relatively earlier, and a set of mature connections have been embodied, which is not discussed specifically in this article.

Compared with the cast-in-place fabricated integral connection, fully fabricated connection(Fig.1) has the advantages of convenient installation, small on-spot workload, fast construction and so on, but for the full prefabricated connection, if only connected by ordinary reinforcement, the rigidity is low, and the overall structure is difficult to be guaranteed. In order to improve the overall stiffness of full prefabricated connections, prestressing is considered to form prestressed fabricated connections, the benefits of which include: firstly, to improve the overall stiffness of structure connection by prestressing tendons; secondly, by prestressing precast connection in the binding site to cause frictional force to resist the beam end shear; thirdly, prestressed reinforcement (unbonded or partly unbonded) under rare earthquake is still elastic to remain a strong self-recovery of the structure. 

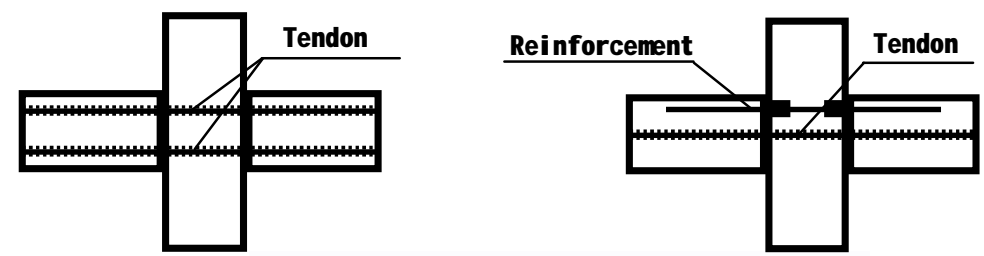

Fig.1 Prestressed Fabricated Connection

If the fabricated connections are connected only through prestressed tendons, their energy dissipation performance is poor, and the structure deformation is large under the action of earthquake, leading to structural damage easily. In order to improve the energy dissipation performance of structures, a hybrid connection which is joined by a prestressed tendon and an energy dissipation device is developed.

At present, many scholars have done a lot of research on prestressed prefabricated connections, and proposed a lot of connections. In this paper, a brief introduction of related research results is presented.

\section{Research Results Overseas}

\section{NIST Research}

In 1987, the association of American National Standards for Science and Technology (NIST) has launched a series of research on the new type of precast reinforced concrete beam column connections, involving the aspects of anti-seismic capacity, construction technology and economy etc., to provides the design basis of precast beam column connection form in frequent seismic zone, and to achieve rapid on-site construction.

Cheok and Lew in 1991 carried out a lot of experimental study on concrete frame beam column connections with bonded precast prestressed tendons[1], the result of which shows that the strength and ductility of the connections are similar to that of cast-in-place beam column connections. When loading to the later stage, the connection is seriously damaged, with great plastic deformation of the prestressed tendon, which leads to greater loss of prestress and greatly reducing the structural integrity.

In order to further improve the stiffness at the later loading period, in 1993, Cheok and Lew [2] changed the prestressing tendon in column region and partial beam region near the column to unbonded form. As a result of this method, the prestressed steel bars can be kept in the elastic stage at all times under large storey displacement, with great prestress remained, thus, the integrity of connections can be guaranteed at all times.

In order to solve the problem of connection energy dissipation, energy dissipation mild steel is added in the precast prestressed beam column connections to improve energy dissipation capacity. The new form of connection is called "mixed" connection. Here are some of the "mixed" connections by NIST.

(1) The upper and lower parts of the beam are made of common steel bars (bonded), and the middle part is bonded with bonded prestressed tendons[3]. The ordinary steel bars on the upper and lower sides of the section bear the main bending moment of the structure, ensuring a better energy dissipation performance in the hysteretic loading. With prestressing tendon in the middle, large prestress can be maintained, which will help to maintain the integrity and the shear bearing capacity of the connections.

(2) The common reinforcement and the prestressing tendon both bear bending moment. The ordinary steel bars and the prestressing tendons are distributed at the upper and lower end of the cross section. The ordinary steel bars are bonded and prestressed tendons are largely deformed without bonding to ensure that they are in an elastic state [3].

(3) Using replaceable non adhesive ordinary steel pipe and prestressed tendon connection. The prestressing tendons are arranged in the middle of the common steel pipe and penetrate through the connections. In order to ensure that the unbonded ordinary steel pipe is both tensile and compressive, 
the $\mathrm{T}$ type anchor is used to anchor the ends of the component. This kind of connection structure has strong energy dissipation capacity, but with complex structure and poor economy efficiency[3] .

\section{PRESSS research projects}

In 1990, the United States and Japan academic and engineering circles, carried out a study on anti-seismic behavior of precast concrete structure, namely PRESSS (Precast Seismic Structural Systems) [4], the main goal of which is to research the applicable seismic zone precast concrete structure and the application of new materials, and through experiment and theoretical research, build the model and the corresponding calculation method. The project is carried out in three stages.

In the first stage through theoretical analysis, the prestressed frame structure is put forward [5-6], the basic components of this system is precast columns and precast prestressed beam, connected by post tensioned prestressed tendons forming friction in the interface of the beam column connection, and bear seismic by frame of beam column structure; through theoretical analysis on the connection study, some frame connection type is selected as the main research direction in the future[7] .

For the second stage, some connections are studied (Priestley M. J. N. 1996[8] and E.I.Sagan, M.E.Kreger1995[9]): linear elastic connection (NE), non linear elastic connection (NLE), tension compression connection (TCY), shear yielding link (SY), Kulun CF (friction connection), which were conducted on the experimental study and from which the hysteretic curves and energy dissipation capacity of various connections are obtained.

The third step is to study the overall mechanical performance of the fully fabricated frame. Priestley and Sritharan 1999 conducted a seismic test of a scale model of five story precast prestressed concrete buildings $[10,11]$. In one direction, there are four seismic frames with different connections, and shear walls in the other direction. The test results show that the damage degree of the fabricated prestressed frame is slightly lower than expected, and the damage degree is smaller than the corresponding cast-in-place concrete frame, showing better energy dissipation capacity. When the inter story displacement of the building is greater than the value required by the code, it still maintains a higher bearing capacity and a better ductility.

\section{Other studies}

In order to improve the energy dissipation performance of unbonded prestressed connections, Morgen, B. G. 2004[12] proposed a form of connection with energy dissipation damper at both ends. In the middle of the connection, the beam column component is connected into a whole by the unbonded prestressed tendons, and the upper and the lower ends of the section are connected by a fan-shaped friction damper. The results show that the connections with friction dampers have better energy dissipation capacity.

A connection construction form proposed by H.A. Spieth 2004[13] et al. The prestressed tendon is anchored on the column, and the inclined prestressed tendon can bear the bending moment of the component section, and also can bear the shear force of the section of the component.

Ozen, 2007[14] five low cyclic reversed loading tests on connections with mixed connections were carried out in 2007. The prestressing tendon is located at half of the height of the beam, and the non prestressed steel bars are respectively arranged at the top of the beam and the bottom of the beam. The results show that with the increase of the content of non prestressed steel bars, the hysteretic behavior of the mixed connections is more and more close to the cast in place connection.

\section{Domestic research results}

$\mathrm{Su}$ Xiaozu et al. conducted the cyclic loading tests of bonded and unbonded prestressed concrete frames in 1987[15], the test results of which show that the plastic hinge can be produced when the prestressed frame is subjected to a large number of repeated loads. The energy consumption of a bonded frame is greater than that of an unbonded frame, but the latter is better than the former in restoration. 。 
Wang Dongyan, 2008[16] carried out reversed cyclic loading experiment to four unbonded tendons fabricated beam, the parameters such as eccentricity, anchorage length and initial prestress were considered. The results showed that the unbonded prestressed precast beam has desirable seismic characteristics, compared with the cast-in-place concrete structure while the energy consumption is low, it has good ductility self-recovery ability (small residual deformation), and lighter damage under nonlinear large displacement.

Dong Tingfeng, 2006[17] carried out reversed cyclic loading experiment to five frame connections, the parameters such as concrete frame connection failure modes, hysteretic characteristics, deformation restoring capacity, displacement ductility and energy dissipation are studied for the unbound prestressed fabricated concrete frame. The results show that the unbonded prestressed precast concrete frame connections have better resistance to expansion, and are better in ductility and resilience than the cast in place connection.

Liu Meng, 2008[18] put forward a rotary lead damper connection and carried out low cyclic reversed loading test. The results show that the number of energy dissipation of dampers installed on the connections is larger than that without dampers, which indicates that dampers play an important role in the consumption of external input energy.

Liu Bingkang et al. carried out the experimental study of prefabricated prestressed concrete frame connections in 2005[19], in order to improve the shear resistance of connections, brackets are set at the connection of beam and column.

Guo Tong, 2012 [20,21], put forward a web friction type of self-centering prestressed concrete frame beam column connection, the connection can be bound though up and down unbonded prestressed tendon, with the damper device arranged on the lateral side of the beam, the friction device can dissipate seismic energy during a relative rotation in beam and column.

Liang Peixin, Guo Zhengxing [22,23], put forward a kind of asymmetric hybrid connection, asymmetric hybrid connections (as seen below) is based on mixed connection forms to further simplify the construction technology, improve the assembly speed, and cancel the lower beam of reinforced. The results show that the hysteretic curve is asymmetrical in shape due to the asymmetrical configuration of ordinary steel bars, and the curve is more plump when forward loading. Therefore, the energy consumption of forward loading is greater than that of negative loading.

Cai Xiaoning et al. 2014[24] designed a self - resetting precast prestressed connection (PTED connection) with an angle steel. A replaceable angle steel is installed on the upper and lower part of the beam column connection as an energy dissipation device, and the unbonded tendon is used in the center to provide the self-resetting performance of the connection.

Guangzhou University, Wu Congxiao, et al. In 2015 [25] proposed a new type of prefabricated fabricated energy dissipation concrete frame structure system, which is composed of fan-shaped lead viscoelastic damper and prefabricated assembled concrete frame. The system connections are designed, and the cyclic loading tests are carried out on the specimens of precast prefabricated beam column connections and the new prefabricated beam column energy dissipation connection specimens. The results show that the new type of prefabricated beam column energy dissipation connection, takes the hysteretic energy dissipation by heciprocating shear deformation through a fan-shaped lead viscoelastic damper, showing better energy dissipation effect, the new connection is has hysteretic curve and good energy dissipation capacity.

Han Jianqiang 2015 [26] carried out low cyclic reversed loading test contrast through the different reinforced ratio of cast-in-place reinforced concrete frame and angle plate prestressed concrete precast concrete frame connections. The results show that the prestressed prefabricated frame structure with additional angle steel plate has better anti-seismic performance.

In order to further improve the energy consumption performance, Han Jianqiang 2015 carried out the cyclic loading test on prestressed precast concrete frame structure connection with damper and cast-in-situ concrete frame connections, and studied the reinforcement concrete frame structure and pretsressed fabricated frame structure connections with damper in terms of the crack distribution, failure mode, hysteretic curve and displacement ductility [27]. 


\section{Conclusions}

Studies at home and abroad show that prestressed concrete frame structure has better anti-seismic performance, but further discussion are still needed,

1) At present, scholars have done a lot of research, putting forward some connection construction forms with better performance in many aspects even better than the whole cast in place connections, but the connection structure is usually complex in practice, needing to be improved and optimized.

3) The structure, layout, location and quantity of dampers are confirmed. In order to improve the energy dissipation capacity of prefabricated prestressed connections, dampers are rurally added. The different locations of dampers directly affect the mechanical performance and energy dissipation effect of the whole structure, and the structure and quantity of the damper relate to the cost of the building. How to optimize the location and number of dampers, so that they can meet the requirements of seismic structure, reasonable force and lower construction costs, needs further analysis and research.

4) Most of the researches on precast prestressed concrete frame structures are rectangular frame beams, and the effect of composite slabs on seismic behavior of frames should be considered;

5) Prestresse in practical engineering is according to the frame structure internal force distribution and by the layout of the curve [], so the stress performance influence of prestressed curve reinforcement on the precast prestressed structure remains further research;

6) At present, the study on progressive collapse of concrete structures by scholars at home and abroad mainly focus on cast in place concrete structure, but still blank in prefabricated concrete structures. How to use new technology in assembly frame, strengthen component connection, and improve the robustness of structure, and meet the requirement of resisting progressive collapse is an issue to be explored.

7) The design method of prestressed concrete frame structures. Due to that the unbonded prestressed tendon remains elastic, without obvious yielding boundaries, and the displacement response of the structure is larger, the strength based design is relatively weak while the performance based design method is better for the displacement control design. Performance-based seismic design theory is a hot topic in earthquake engineering, with still many key problems to be solved before put into practice.

\section{Acknowledgements}

This work was financially supported by the China state construction technical center R\&D of Science and Technology Foundation (CSCEC-2015-JQ-01).

\section{References}

[1] Cheok G S, Lew H S. Performance of precast concrete beam-to-column connections subject to cyclic loading[J]. PCI Journal, 1991, 36(3): 56-67.

[2] Cheok G S, Lew H S. Model precast concrete beam-to-column connections subject to cyclic loading[J]. PCI Journal, 1993, 38(4): 80-92.

[3] Cheok, G. S., and Lew, H. S., "Performance of 1/3-Scale Model Precast Concrete Beam-Column Connections Subjected to Cyclic Inelastic Loads" Report No.3,NISTIR 5246, National Institute of Standards and Technology, Gaithersburg, MD, June 1993.

[4] Priestley M J N. Overview of PRESSS research program[J]. PCI journal, 1991, 36(4): 50-57.

[5] Englekirk R E. Seismic design considerations for precast concrete multistory buildings[J]. PCI Journal, 1990, 35(3): 40-51.

[6] Nakaki S D, Englekirk R E. PRESSS Industry Seismic Workshops: Concept Development[J]. PCI JOURNAL, 1991, 36(5): 54-61.

[7] Stanton J F, Hawkins N M, Hicks T R. PRESSS Project 1.3: Connection Classification and Evaluation[J]. PCI Journal, 1991, 36(5): 62-71. 
[8] Englekirk R E. Seismic design considerations for precast concrete multistory buildings[J]. Pci Journal, 1990, 35(3): 40-51.

[9] Nakaki S D, Englekirk R E. PRESSS Industry Seismic Workshops: Concept Development[J]. PCI JOURNAL, 1991, 36(5): 54-61.

[10] Priestley M J N, Sritharan S, Conley J R, et al. Preliminary results and conclusions from the PRESSS five-story precast concrete test building[J]. PCI journal, 1999, 44(6): 42-67.

[11]Nakaki S D, Stanton J F, Sritharan S. An overview of the PRESSS five-story precast test building[J]. PCI journal, 1999, 44(2): 26-39.

[12] Morgen B, Kurama Y. A friction damper for post-tensioned precast concrete beam-to-column joints[J]. PCI J, 2004, 49(4): 112-133.

[13] Spieth H A, Arnold D, Davies M, et al. Seismic performance of post-tensioned precast concrete beam to column connections with supplementary energy dissipation[C]//2004 NZSEE Conference. 2004.

[14] Ozden S, Ertas O. Behavior of unbonded, post-tensioned, precast concrete connections with different percentages of mild steel reinforcement[J]. PCI journal, 2007, 52(2): 32-44.

[15] Su X. Cyclic Loading Test and Full Range FEM Analysis of Prestressed Concrete Frames[J]. Journal of Tongji University, 1987.

[16] Wang D, Hang Y. Experimental research on unbonded post-tensioned precast concrete beams[J]. Industrial Construction, 2008, 38(2):31-182.

[17]Dong T F, Li Z B, Zhou X Y, et al. Experimental study on seismic performances of precast prestressed concrete beam-to-column connections with unbonded tendons[J]. Journal of Beijing University of Technology, 2006, 32(2):144-143.

[18] Liu M. Study on new lead dampers and seismic behavior of prestress assembling beam-column connections[D]. Beijing University of Technology, 2008.

[19] Liu B, Zhang Y, Jin Z, et al. Experimental study on seismic behavior of prestressed fabricated PC frame connections[J]. Journal of Building Structures, 2005, 26(2):60-65.

[20] Guo T, Song L, Zhang G, et al. Experimental study on beam-column connections of self-centering prestressed concrete frame with web friction devices[J]. China Civil Engineering Journal, 2012, 45(6):23-32.

[21] Song L L, Guo T, Gu Y, et al. Experimental study of a self-centering prestressed concrete frame subassembly[J]. Engineering Structures, 2015, 88: 176-188.

[22]Liang P, Guo Z. Experimental Study on New Prefabricated Unsymmetrical Hybrid Subassemblages[J]. Construction Technology, 2010.

[23] Liang P, Guo Z. Study on the performance of unsymmetrical hybrid connection interface of the beam and column[J]. Building Structure, 2011, 41(10):84-88.

[24] Cai X N, Meng S P, Sun W W. experimental study on performance of components of the exterior self-centering post-tensioned precast connections[J]. Engineering Mechanics, 2014, 2(2):184-199.

[25] Wu C, Lai W, Yun Z, et al. Experimental study on seismic behaviors of new energy-dissipative prefabricated concrete frame structure joints[J]. China Civil Engineering Journal, 2015.

[26] HAN J Q, YANG Na. Experimental study on prestressed assembling frame midside node with additional angle steel under different prestressing force [J]. World Earthquake Engineering, 2015(2):179-182.

[27] HAN J Q, PEI Y H.et al. Experimental Study on Seismic Performance of Assembled Prestressed Concrete Structure Beam-column Joints with Dampers [J]. Structural Engineers, 2015, 31(6):152-157. 